\title{
Efeito da aplicação de silicato de cálcio no crescimento, no estado nutricional e na produção de matéria seca de mudas de maracujazeiro
}

Renato de M. Prado ${ }^{1} \&$ William Natale ${ }^{2}$

\begin{abstract}
1 Depto. de Solos e Adubos, FCAV/UNESP. Via de Acesso Prof. Paulo D. Castellane, s/n., CEP 14870-000, Jaboticabal, SP, Brasil. Bolsista do CNPq. E-mail: rmprado@fcav.unesp.br (Foto)

2 FCAV/UNESP. Bolsista CNPq. E-mail: natale@fcav.unesp.br.
\end{abstract}

Protocolo 183 - 18/11/2003 - Aprovado em 7/6/2004

\begin{abstract}
Resumo: Objetivou-se, com este trabalho, avaliar os efeitos da aplicação de um resíduo industrial (silicato de cálcio) ao substrato de produção das mudas de maracujazeiro, como material corretivo, no desenvolvimento, na produção de matéria seca e no estado nutricional das plantas. $O$ delineamento experimental foi em blocos ao acaso, com cinco tratamentos e quatro repetições. As doses de silicato de cálcio foram aplicadas objetivando-se elevar a percentagem de saturação com bases 25, 50, 75 e 100\%, correspondendo a 0,45; 0,90; 1,35 e 1,80 g por vaso, respectivamente, além da testemunha sem aplicação. A unidade experimental foi constituída por vasos com $2 \mathrm{dm}^{3}$ de substrato de um Latossolo Vermelho distrófico. Após 80 dias da semeadura avaliaram-se: a altura, o número de folhas, o diâmetro do caule e a matéria seca da parte aérea e das raízes e, também, os teores de macro e micronutrientes. O resíduo de silicato de cálcio mostrou-se como corretivo de acidez do solo e como fonte de $\mathrm{Ca}$, embora ineficiente fonte de Mg. O maior crescimento das mudas de maracujazeiro esteve associado à saturação por bases do solo de $58 \%$, à concentração de Ca do solo de $19 \mathrm{mmol}_{\mathrm{c}} \mathrm{dm}^{-3}$ e teores de Ca na parte aérea de $12,0 \mathrm{~g} \mathrm{~kg}^{-1}$.
\end{abstract}

Palavras-chave: calagem, acidez, Passiflora edulis

\section{Effect of application of calcium silicate on growth, nutritional status and dry matter production of passion fruit seedlings}

\begin{abstract}
This work was carried out with the objective of evaluating the effect of the addition of industrial residue (calcium silicate) to the substrate in the production of the passion fruit seedlings, studying the benefits in the development, the production of dry matter and the nutritional state of the plants. The experimental design adapted was a randomized block with 5 treatments and 4 repetitions. The doses of calcium silicate applied were equivalent to raise in half; one; one and half; and twice the dose to elevate percentage of base saturation $=50 \%$, corresponding to the $0 ; 0.45 ; 0.90 ; 1.35$ and $1.80 \mathrm{~g}$ per pot, respectively, besides a control without application. The experimental unit was constituted of pots with $2 \mathrm{dm}^{3}$ of a Red Latossol (Oxisol). After 80 days of the plantation, the height, stem diameter, number of leaves and the dry matter of the shoot and the root, as well as contents of macro and micronutrients were evaluated. The passion fruit seedlings responded to the calcium silicatie application. The maximum development was associated with the base saturation of $58 \%$ with the concentrations of $\mathrm{Ca}$ in the soil equivalent to $19 \mathrm{mmol}_{\mathrm{c}}$ $\mathrm{dm}^{-3}$ and the content of $\mathrm{Ca}$ in the shoot of $12.0 \mathrm{~g} \mathrm{~kg}^{-1}$.
\end{abstract}

Key words: liming, acidity, Passiflora edulis.

\section{INTRODUÇÃO}

Atualmente, têm sido amplamente discutidos estudos que poderiam indicar a viabilidade de uso de resíduos industriais na agricultura, mas, para tornar possível o uso desses resíduos, são necessários estudos agronômicos para indicar os efeitos positivos no sistema solo-planta, seja como material corretivo ou fonte de nutrientes; assim, estudos indicam viabilidade agronômica para diversos resíduos, como biossólidos (lodo de esgoto) (Oliveira et al., 1995), vinhaça (Almeida, 1952), escória de siderurgia (Prado et al., 2001) e composto de lixo (Berton, 1996); entretanto, inexistem estudos com resíduo industrial à base de silicato de cálcio. 
Neste sentido, há indústrias de produção de placas especiais com determinadas características técnicas (isolante térmico e sonoro; incombustível, rigidez e com boa usinabilidade), para aplicação na construção civil e naval, que utilizam, como matéria-prima, o silicato de cálcio e fibras minerais não-amianto. Como resíduo do processo industrial (usinagem), tem-se o silicato de cálcio, na forma de pó. O silicato de cálcio é conhecido como material corretivo (Alcarde, 1992), podendo apresentar características de correção da acidez do solo e fonte de bases, semelhante aos calcários. Por outro lado, os solos tropicais são reconhecidamente ácidos, com elevada saturação por alumínio. A prática da calagem promove a precipitação do $\mathrm{Al}$ do solo, aumentando o valor $\mathrm{pH}$ e a concentração de bases como $\mathrm{Ca}$ e $\mathrm{Mg}$, possibilitando a proliferação intensa das raízes, maior absorção de nutrientes pelas plantas. A importância do sistema radicular das plantas é significativa, visto haver uma estreita dependência entre o desenvolvimento das raízes e a formação da parte aérea. Este fato é muito importante em mudas na fase de pós-plantio no campo, podendo aumentar a taxa de pegamento e o estabelecimento mais rápido, com reflexos na precocidade de produção dos pomares; assim, para uma eficiente produção de mudas, o uso de corretivos da acidez do solo pode favorecer a obtenção de plantas com qualidade e estado nutricional adequado.

Salienta-se que, como os preços do silicato são relativamente baixos comparados aos dos demais insumos, podese alcançar uma alta relação benefício/custo, com maior sustentabilidade nos sistemas de produção.

Diante do contexto procurou-se, com este trabalho, avaliar o efeito da aplicação de silicato nos atributos químicos do solo e na nutrição e produção de mudas de maracujazeiro.

\section{MATERIAL E MÉTODOS}

O presente trabalho foi conduzido em condições de casa de vegetação, na Faculdade de Ciências Agrárias e Veterinárias, UNESP, Jaboticabal, SP, no qual se utilizou, como substrato, o subsolo de um Latossolo Vermelho distrófico (camada 3-4 m). Realizaram-se análises químicas do substrato, antes da aplicação do silicato de cálcio e após 60 dias de incubação, por ocasião da semeadura (Tabela 1).

Utilizou-se o silicato de cálcio com as seguintes características: $\mathrm{CaO}=275,3 \mathrm{~g} \mathrm{~kg}^{-1} ; \mathrm{MgO}=17,5 \mathrm{~g} \mathrm{~kg}^{-1} ; \mathrm{PN}=53,6 \%$; $\mathrm{RE}=100 \%$ e PRNT $=53,6 \%$. O delineamento experimental adotado foi em blocos casualizados, com cinco tratamentos (zero; metade; uma vez; uma vez e meia e duas vezes; a dose para elevar o $\mathrm{V}=50 \%$, correspondendo a $0 ; 0,45 ; 0,90 ; 1,35 \mathrm{e}$ $1,80 \mathrm{~g}$ por vaso, respectivamente) e quatro repetições. A capacidade total do vaso foi de $2,3 \mathrm{dm}^{3}$; entretanto, foi preenchido com $2,0 \mathrm{dm}^{3}$ de substrato.

Para semeadura, cada unidade experimental recebeu dose de nivelamento para $\mathrm{P}\left(450 \mathrm{mg} \mathrm{dm}^{-3}\right)$ conforme indicação de Machado (1998), $\mathrm{N}\left(300 \mathrm{mg} \mathrm{dm}^{-3}\right), \mathrm{K}\left(150 \mathrm{mg} \mathrm{dm}^{-3}\right), \mathrm{Zn}\left(5 \mathrm{mg} \mathrm{dm}^{-3}\right)$ e $\mathrm{B}\left(0,5 \mathrm{mg} \mathrm{dm}^{-3}\right)$, de acordo com a recomendação geral para ensaios em vasos (Malavolta, 1981), na forma de superfosfato triplo ( $44 \%$ de $\left.\mathrm{P}_{2} \mathrm{O}_{5}\right)$, sulfato de amônio $(20 \% \mathrm{de} \mathrm{N})$, cloreto de potássio $\left(60 \%\right.$ de $\left.\mathrm{K}_{2} \mathrm{O}\right)$, sulfato de zinco $(22 \%$ de $\mathrm{Zn})$ e ácido bórico $(17 \%$ de $\mathrm{B})$ respectivamente. $\mathrm{O} \mathrm{N}$ e o $\mathrm{K}$ foram parcelados em três aplicações aos 30, 45 e 60 dias após o plantio. O P, o Zn e o B foram adicionados em dose total na semeadura.

Empregaram-se cinco sementes do maracujazeiro-amarelo por vaso e, uma semana após a emergência das plântulas, realizou-se o desbaste, deixando-se 3 mudas por vaso até o final do experimento. Optou-se por trabalhar com 3 plantas por vaso para tentar reduzir o componente da variabilidade genética das plantas, intrínseca em plantas propagadas por sementes.

A irrigação foi mantida contínua durante o período experimental, tomando-se por base a umidade correspondente a $70 \%$ da capacidade de campo do solo.

Aos 80 dias após a semeadura, avaliaram-se as variáveis biológicas indicativas do desenvolvimento das plantas, altura, diâmetro do caule, número de folhas, peso da matéria seca da parte aérea e das raízes do maracujazeiro. Na mesma ocasião, o estado nutricional das plantas foi avaliado, dividindo-se as mudas em parte aérea e raízes. As determinações dos teores de macro e micronutrientes no tecido vegetal seguiram a metodologia de Bataglia et al. (1983). Amostragens do substrato foram realizadas na mesma época e as determinações analíticas seguiram as recomendações de Raij et al. (2001).

Com base nos resultados obtidos, realizaram-se análises de variância para as diversas variáveis estudadas, e a análise de regressão entre os tratamentos e as determinações no solo e na planta.

\section{RESULTADOS E DISCUSSÃO}

\section{Efeito dos tratamentos no solo}

O efeito da aplicação do silicato ao substrato promoveu a neutralização da acidez do solo, elevando a saturação por bases, mas se empregando apenas o dobro da dose, atingiu-se

Tabela 1. Propriedades químicas do substrato $^{(*)}$ de um Latossolo Vermelho distrófico, utilizado na produção de mudas de maracujazeiro

\begin{tabular}{|c|c|c|c|c|c|c|c|c|c|c|}
\hline $\begin{array}{c}\text { Dose } \\
\text { g vaso }^{-1}\end{array}$ & $\mathrm{pH}\left(\mathrm{CaCl}_{2}\right)$ & $\begin{array}{l}\mathrm{MO} \\
\mathrm{g} \mathrm{dm}^{-3}\end{array}$ & $\begin{array}{l}\mathrm{P} \text { (resina) } \\
\mathrm{mg} \mathrm{dm}^{-3}\end{array}$ & \multicolumn{6}{|c|}{$\mathrm{mmol}_{\mathrm{c}} \mathrm{dm}^{-3}$} & $\begin{array}{l}\mathrm{V} \\
\%\end{array}$ \\
\hline \multicolumn{11}{|c|}{ Antes da Aplicação do Silicato de Cálcio } \\
\hline 0 & 4,4 & 7 & 2 & 0,5 & 4 & 2 & 16 & 6,5 & 22,5 & 29 \\
\hline \multicolumn{11}{|c|}{ Época da Semeadura } \\
\hline 0,45 & 5,0 & 3 & 68 & 0,8 & 8 & 2 & 16 & 10,8 & 26,8 & 40 \\
\hline 0,90 & 5,1 & 3 & 68 & 0,8 & 10 & 2 & 15 & 12,8 & 27,8 & 46 \\
\hline 1,35 & 5,2 & 5 & 80 & 0,6 & 17 & 2 & 12 & 19,6 & 31,6 & 62 \\
\hline 1,80 & 5,4 & 5 & 79 & 0,8 & 23 & 3 & 13 & 26,8 & 39,8 & 67 \\
\hline
\end{tabular}

"O substrato é resultado da mistura da camada de 3-4 m do perfil do solo, utilizado na produção das mudas 
o V igual a 67\%, (Tabela 1); uma das causas que explicam este fato é relatada por Tescaro (1998), que sinaliza que esta ineficiência em elevar o $\mathrm{V} \%$ a valores relativamente altos, pode estar ligada ao alto potencial de cargas dependentes do $\mathrm{pH}$ do solo, ao deslocamento da reação de equilíbrio da solubilização do corretivo e, ainda, à formação de novos minerais no solo, em forma de hidróxidos pouco solúveis. Nota-se, que na época da semeadura a concentração de $P$ do solo atingiu $80 \mathrm{mg} \mathrm{dm}^{-3}$, devido à aplicação do adubo fosfatado (Tabela 1).

Acompanhando a evolução dos efeitos da aplicação do silicato ao solo aos 80 dias após a semeadura, verificou-se aumento do valor $\mathrm{pH}$ (Figura 1A) e diminuição da concentração de $\mathrm{H}+\mathrm{Al}$ (Figura 1B) e aumento do Ca (Figura 1C) e do valor da soma de bases (Figura 1D) e da saturação por bases (Figura $1 \mathrm{E})$; entretanto, não houve alteração significativa para a concentração de $\mathrm{Mg}$ do solo (Figura 1C). Esses efeitos da escória na correção da acidez do solo e no aumento de bases são devidos à presença do constituinte neutralizante $\left(\mathrm{SiO}_{3}^{-2}\right) \mathrm{e}$ de Ca e Mg no material, respectivamente (Alcarde, 1992). Assim, esses resultados indicam que, apesar do resíduo se apresentar como corretivo de acidez do solo, não se mostrou eficiente como fonte de magnésio.

Observou-se que a aplicação do silicato de cálcio diminuiu a concentração dos micronutrientes do solo, como o $\mathrm{Cu}\left(\mathrm{y}=0,15-0,03 \mathrm{x}, \mathrm{R}^{2}=0,95^{* *}\right) ; \mathrm{Fe}\left(\mathrm{y}=3,07-0,08 \mathrm{x}+0,022 \mathrm{x}^{2}\right.$, $\left.\mathrm{R}^{2}=0,80 *\right) ;$ o $\mathrm{Mn}\left(\mathrm{y}=1,89-0,38 \mathrm{x}, \mathrm{R}^{2}=0,99 * *\right)$ e o $\mathrm{Zn}(\mathrm{y}=1,18$ $\left.-0,33 \mathrm{x}, \mathrm{R}^{2}=0,84^{* *}\right)$ e o $\mathrm{B}\left(\mathrm{y}=0,42-0,101 \mathrm{x}, \mathrm{R}^{2}=0,95^{* *}\right)$. A diminuição da concentração dos micronutrientes (metálicos) do solo com aumento do $\mathrm{pH}$ é amplamente relatada na literatura. Segundo Raij (1991) a diminuição da acidez do solo promove insolubilização de micronutrientes, por meio da formação de óxidos. O Mn trocável e o da solução se convertem em $\mathrm{Mn}^{+3} \mathrm{e}$ $\mathrm{Mn}^{+4}$ insolúveis. O B tem sua disponibilidade aumentada até certo valor $\mathrm{pH}$ quando, então, se formam compostos com a matéria orgânica de baixa solubilidade. No caso do zinco, Vale et al. (1997) complementam que o cálcio é um potente deslocador do $\mathrm{Zn}$ de complexos e quelatos, deixando o zinco livre na solução, o que favorece sua precipitação como $\mathrm{Zn}(\mathrm{OH})_{2}$.

\section{Efeito dos tratamentos sobre o crescimento e a produção de matéria seca}

A aplicação de silicato aumentou de forma quadrática o crescimento das mudas de maracujazeiro, para a altura e número de folhas (Figura 2A) e para o diâmetro do caule (Figura 2B). Esta relação positiva entre a altura e o diâmetro do caule foi relatada também por Ferri (1985) que indica tratar-se de variáveis de grande importância morfofisiológica, visto que refletem de modo prático no crescimento da planta.

$\mathrm{O}$ aumento quadrático da matéria seca da parte aérea e das raízes das plantas refletiu o maior crescimento das mudas de maracujazeiro (Figura 3A); portanto, este resultado indica a resposta positiva da fruteira à neutralização da acidez do solo, concordando com Mendonça et al. (1999) que observaram a sensibilidade do maracujazeiro à acidez discordando, porém, de Fonseca et al. (2002) que não obtiveram resposta das plantas à calagem em solo com saturação por bases superior a $40 \%$. Isto indica que, embora o maracujazeiro responda à aplicação de um corretivo de acidez do solo, é importante que a

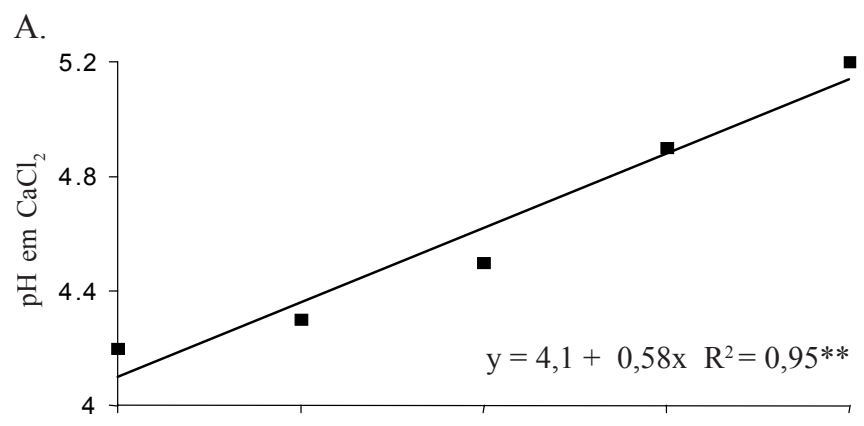

B.

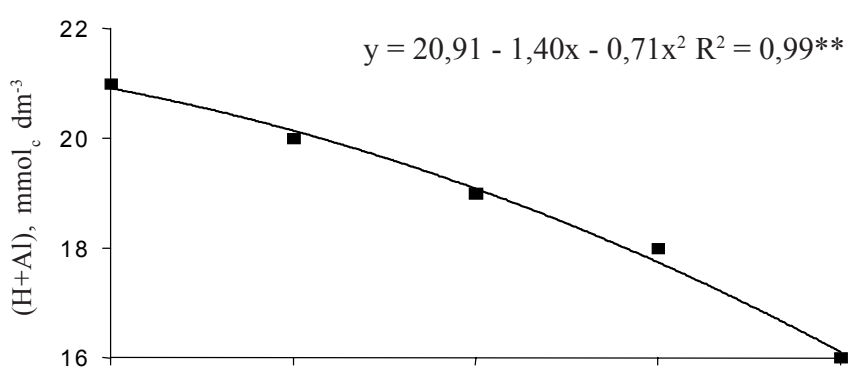

C.

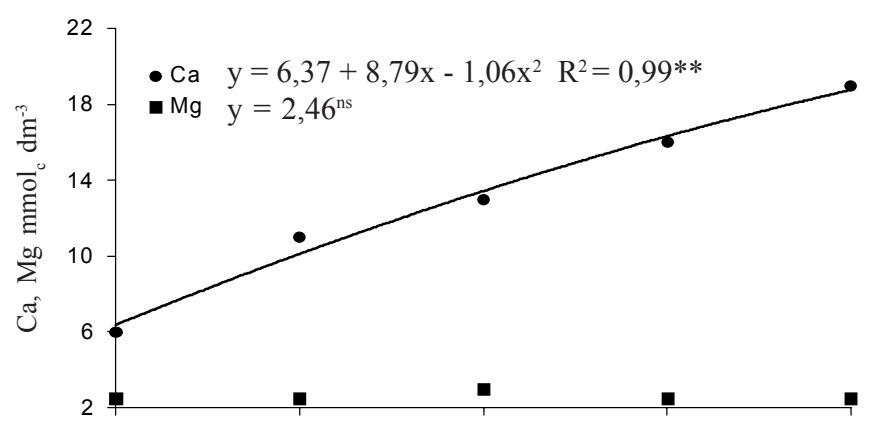

D.

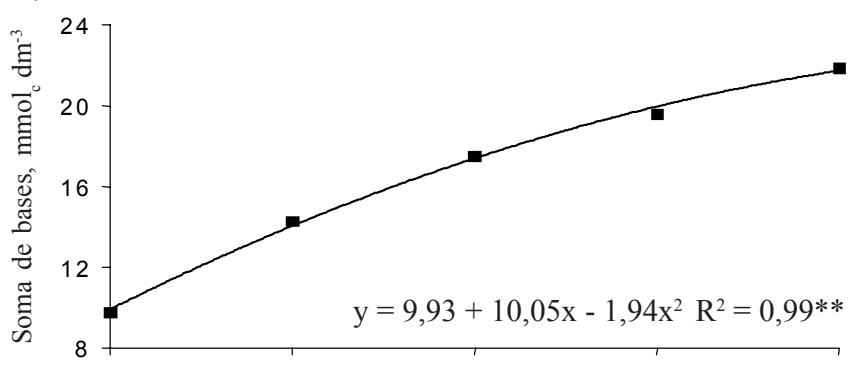

E.

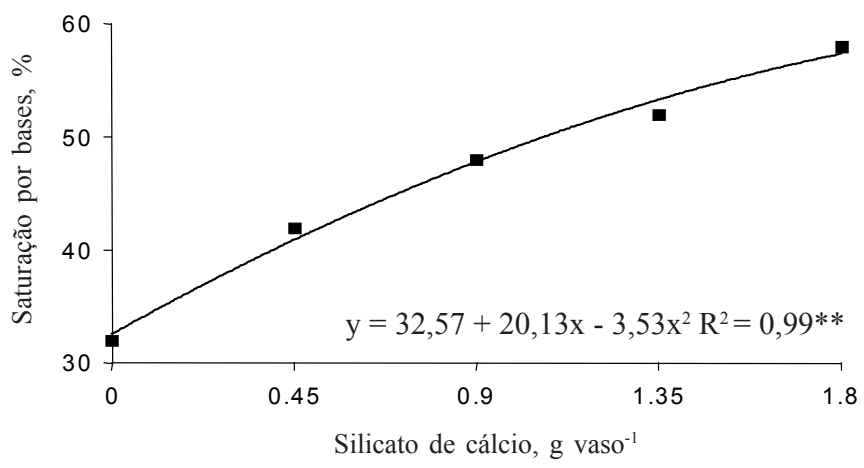

Figura 1. Efeito da aplicação de silicato sobre o valor $\mathrm{pH}(\mathrm{A})$, concentração de $\mathrm{H}+\mathrm{Al}$ (B), de $\mathrm{Ca}$ e $\mathrm{Mg}$ (C), e na soma de bases (D) e saturação por bases (E), aos 80 dias após a semeadura das mudas de maracujazeiro, em substrato do Latossolo Vermelho distrófico. 

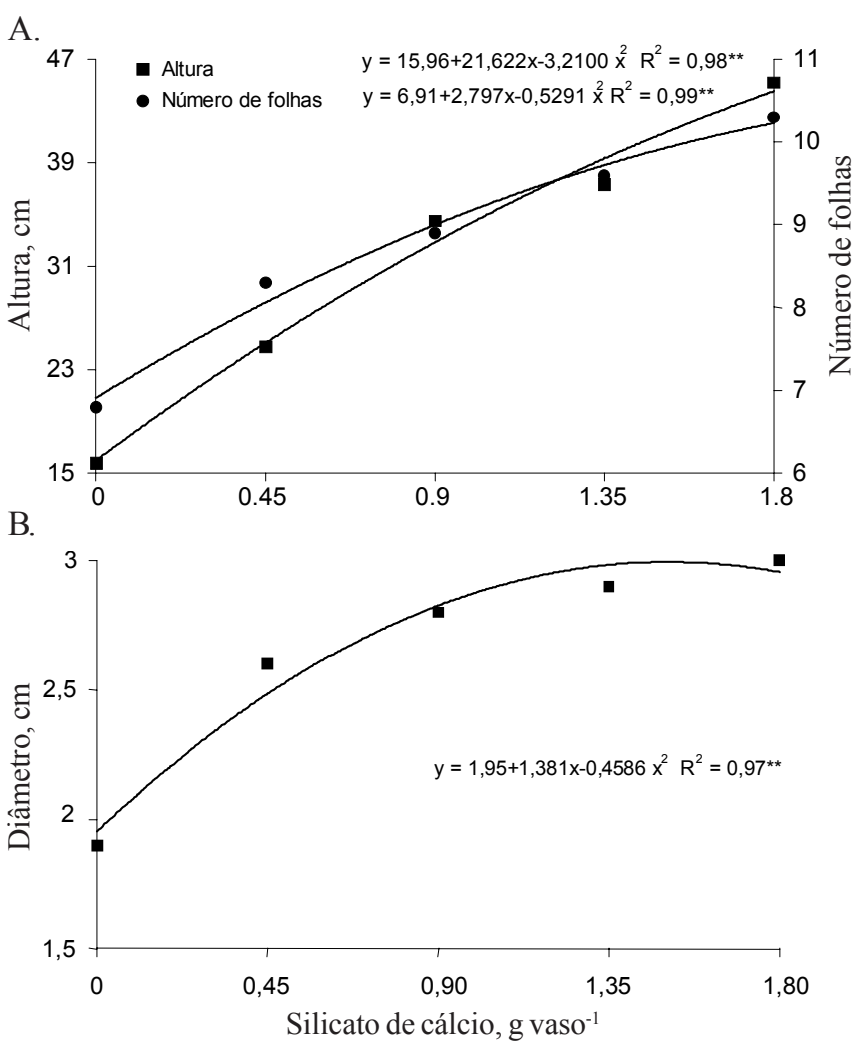

Figura 2. Efeito da aplicação de silicato em substrato do Latossolo Vermelho distrófico na altura e número de folhas (A) e no diâmetro do caule (B), das mudas de maracujazeiro, aos 80 dias após a semeadura

experimentação utilize solos com elevada acidez e baixa concentração de bases, como no presente caso $(\mathrm{Ca}=4$ e $\mathrm{Mg}=$ $2 \mathrm{mmol}_{\mathrm{c}} \mathrm{dm}^{-3} ; \mathrm{V}=29 \%$ ) da Tabela 1, apresentando condições de avaliação da reação dos genótipos à correção da acidez do solo, bem como seus reflexos no crescimento das plantas. Em solos com fertilidade maior, as doses de um material corretivo podem elevar muito o valor $\mathrm{pH}$ e a concentração de bases, insolubilizando micronutrientes e causando prejuízos à produção.

Analisando-se a relação solo x produção, notou-se que a máxima produção de matéria seca total esteve associada à saturação por bases do solo de 58\% (Figura 3B). Assim, este resultado discorda da recomendação de Piza Júnior et al. (1996) para o estado de São Paulo e de Lima (1999), em estudos realizados na Bahia, que indicam a saturação por bases ideal para o maracujazeiro igual a 80 e $70 \%$, respectivamente. Esta diferença se deve, sem dúvida, aos aspectos da planta e de cultivo, sendo que no presente estudo se trabalhou com a fase de mudas e em condições de vasos enquanto a recomendação dos referidos autores é para a fase adulta, no campo.

\section{Efeito dos tratamentos no estado nutricional das mudas}

Aplicação de silicato afetou significativamente os teores de macro e micronutrientes na parte aérea e nas raízes das mudas de maracujazeiro (Tabela 2). Observou-se que os teores de N, P, K, Mg, S e B não foram afetados de maneira significativa, enquanto diminuiu o teor de $\mathrm{Cu}, \mathrm{Fe}, \mathrm{Mn}$ e $\mathrm{Zn}$ e aumentou de $\mathrm{Ca}$ com a aplicação do silicato. Esses incrementos nos teores de
A.

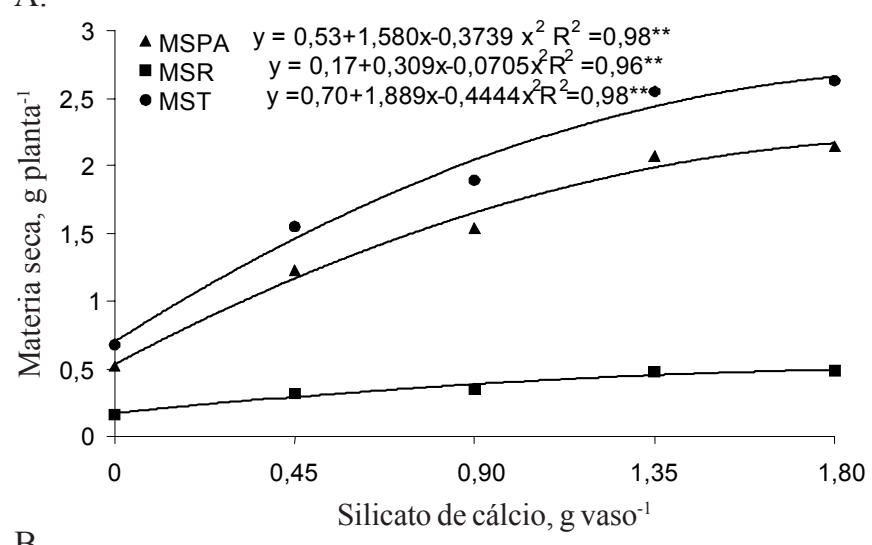

B.

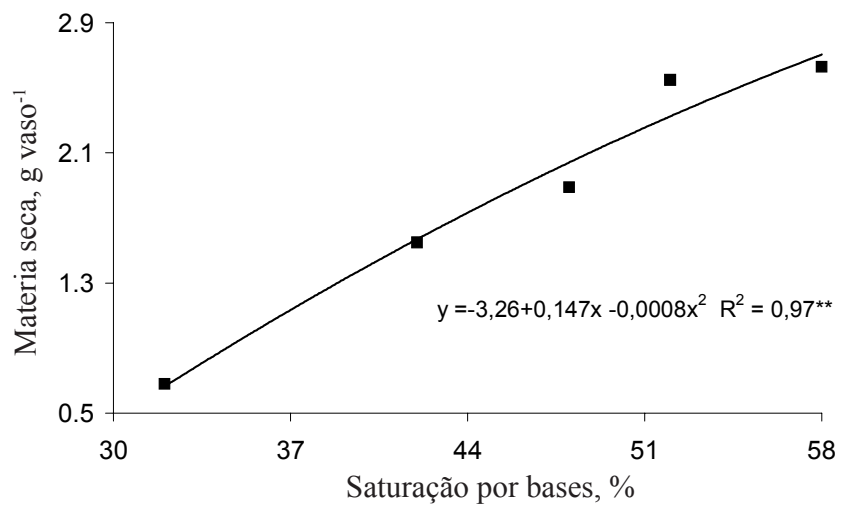

Figura 3. Efeito da aplicação de silicato ao substrato do Latossolo Vermelho sobre a produção de matéria seca da parte aérea e das raízes (A) e a relação entre a saturação por bases do solo e a produção de matéria seca (parte aérea, raízes e total) das mudas de maracujazeiro (B), aos 80 dias após a semeadura

Ca na parte área (PA) das mudas são explicados pelo aumento desse nutriente no solo, devido à aplicação do silicato que possui, em sua composição, esse cátion. Constatou-se a seguinte relação quadrática: $\mathrm{Ca}_{(\mathrm{PA})}=1,700+0,512 \mathrm{Ca}_{(\text {solo) }}+[0,003$ $\left.\mathrm{Ca}_{(\text {solo) }}\right]^{2}, \mathrm{R}^{2}=0,99 * *$. Resultados semelhantes foram obtidos nas raízes, sendo que a aplicação de silicato não alterou significativamente os teores de $\mathrm{N}, \mathrm{P}, \mathrm{K}, \mathrm{Mg}, \mathrm{S}$ e Fe; entretanto, diminuiu os teores de $\mathrm{B}, \mathrm{Cu}, \mathrm{Mn}$ e $\mathrm{Zn}$ e aumentou o de $\mathrm{Ca}$.

Esses efeitos no incremento dos teores de $\mathrm{Ca}$ e diminuição nos teores de micronutrientes, também foram obtidos por Fonseca et al. (2002) na parte aérea de mudas de maracujazeiro submetidas a aplicação de calcário.

Quanto ao acúmulo dos nutrientes na parte aérea (PA) e nas raízes $(\mathrm{R})$ das mudas de maracujazeiro notou-se, em função da aplicação de silicato (x), um incremento quadrático para o cálcio:

$$
\begin{gathered}
\mathrm{Ca}_{(\mathrm{PA})}=2,68+13,422 \mathrm{x}, \mathrm{R}^{2}=0,98 * * \\
\mathrm{Ca}_{(\mathrm{R})}=0,28+1,311 \mathrm{x}, \mathrm{R}^{2}=0,98 * *
\end{gathered}
$$

Para os micronutrientes também houve redução significativa no acúmulo desses elementos com a aplicação do silicato, apresentando comportamento quadrático na parte aérea e nas raízes, para o $\mathrm{Cu}, \mathrm{Mn}, \mathrm{Zn}$ e Fe: 
Tabela 2. Teores de macro e micronutrientes na parte aérea e raízes de mudas de maracujazeiro, em função da aplicação de silicato

\begin{tabular}{|c|c|c|c|c|c|c|c|c|c|c|c|}
\hline \multirow{2}{*}{$\begin{array}{c}\text { Dose } \\
\text { g } \text { vaso }^{-1}\end{array}$} & $\mathrm{~N}$ & $\mathrm{P}$ & $\mathrm{K}$ & $\mathrm{Ca}$ & $\mathrm{Mg}$ & $\mathrm{S}$ & B & $\mathrm{Cu}$ & $\mathrm{Fe}$ & $\mathrm{Mn}$ & $\mathrm{Zn}$ \\
\hline & \multicolumn{6}{|c|}{$\mathrm{g} \mathrm{kg}^{-1}$} & \multicolumn{5}{|c|}{$\mathrm{mg} \mathrm{kg}^{-1}$} \\
\hline & \multicolumn{11}{|c|}{ Parte Aérea } \\
\hline 0,45 & 37,6 & 2,0 & 25,8 & 7,6 & 1,4 & 1,7 & 10 & 3 & 75 & 136 & 50 \\
\hline 0,90 & 37,0 & 2,1 & 23,0 & 8,7 & 1,4 & 1,7 & 11 & 3 & 68 & 112 & 34 \\
\hline 1,35 & 31,8 & 2,1 & 23,0 & 10,8 & 1,8 & 1,7 & 10 & 2 & 63 & 101 & 32 \\
\hline $\mathrm{RL}$ & & & & $247,9 * *$ & - & & - & $75,1 * *$ & $17,4 * *$ & $71,5 * *$ & - \\
\hline RQ & & & & - & - & & - & - & - & - & $5,3 *$ \\
\hline \multirow[t]{2}{*}{ CV(\%) } & 9,7 & 8,8 & 9,0 & 8,2 & 15,0 & 16,0 & 7,1 & 17,9 & 17,5 & 10,9 & 9,2 \\
\hline & \multicolumn{11}{|c|}{ Raízes } \\
\hline 0 & 23,0 & 1,7 & 22,4 & 2,3 & 1,0 & 1,7 & 50 & 15 & 92 & 272 & 77 \\
\hline 1,80 & 22,1 & 1,8 & 15,0 & 5,5 & 1,1 & 1,6 & 24 & 8 & 89 & 225 & 50 \\
\hline Teste F & $0,4^{\mathrm{ns}}$ & $1,9^{\mathrm{ns}}$ & $2,1^{\mathrm{ns}}$ & $45,9 * *$ & $1,4^{\mathrm{ns}}$ & $1,3^{\mathrm{ns}}$ & $52,9 * *$ & $4,2 *$ & $1,0^{\mathrm{ns}}$ & $9,2 * *$ & $9,2 * *$ \\
\hline $\mathrm{RL}$ & & & & $177,5^{* *}$ & & & $173,9^{* *}$ & $16,3 * *$ & & $32,3 * *$ & $36,3 * *$ \\
\hline RQ & & & & & & & - & & & & \\
\hline CV (\%) & 14,6 & 10,2 & 20,2 & 10,5 & 17,1 & 16,5 & 10,2 & 25,4 & 14,8 & 11,7 & 11,7 \\
\hline
\end{tabular}

$$
\begin{aligned}
& \mathrm{Cu}_{(\mathrm{PA})}=0,002+0,005 \mathrm{x}-0,003 \mathrm{x}^{2}, \mathrm{R}^{2}=0,73^{*} \\
& \mathrm{Cu}_{(\mathrm{R})}=0,002+0,003 \mathrm{x}-0,001 \mathrm{x}^{2}, \mathrm{R}^{2}=0,85^{* *} \\
& \mathrm{Mn}_{(\mathrm{PA})}=0,080+0,197 \mathrm{x}-0,081 \mathrm{x}^{2}, \mathrm{R}^{2}=0,92^{* *} \\
& \mathrm{Mn}_{(\mathrm{R})}=0,050+0,074 \mathrm{x}-0,020 \mathrm{x}^{2}, \mathrm{R}^{2}=0,93 * * \\
& \mathrm{Zn}_{(\mathrm{PA})}=0,030+0,050 \mathrm{x}-0,019 \mathrm{x}^{2}, \mathrm{R}^{2}=0,76^{*} \\
& \mathrm{Zn}_{(\mathrm{R})}=0,01+0,0181 \mathrm{x}-0,0063 \mathrm{x}^{2} \mathrm{R}^{2}=0,92^{* *} \\
& \mathrm{Fe}_{(\mathrm{PA})}=0,04+0,115 \mathrm{x}-0,042 \mathrm{x}^{2}, \mathrm{R}^{2}=0,95^{* *} \\
& \mathrm{Fe}_{(\mathrm{R})}=0,02+0,028 \mathrm{x}-0,007 \mathrm{x}^{2} \mathrm{R}^{2}=0,96^{* *}
\end{aligned}
$$

Assim, o acúmulo de micronutrientes $(\mathrm{Cu}, \mathrm{Mn}, \mathrm{Zn}$ e $\mathrm{Fe})$ nas mudas, teve comportamento quadrático, ou seja, um acréscimo inicial e, depois, diminuição nas maiores dosagem do resíduo; entretanto, o teor desses micronutrientes apresentou diminuição linear com a aplicação do resíduo, conforme a Tabela 2, o que indica a presença do efeito de diluição sendo que, com o crescimento das plantas, houve diluição dos nutrientes. Salienta-se, então, que apenas nas doses máximas do silicato é que ocorreu diminuição significativa no acúmulo desses micronutrientes. Os efeitos do resíduo na diminuição da absorção e acúmulo de micronutrientes pelas plantas, podem ser explicados pelos efeitos deste silicato na diminuição da concentração dos referidos micronutrientes no solo, conforme já discutido.

Observou-se, também, relação positiva entre o Ca na parte aérea (PA) e na raiz (R) e a produção de matéria seca total (MST) das mudas de maracujazeiro:

$$
\begin{gathered}
\mathrm{MST}=-1,66+0,551 \times \mathrm{Ca}_{(\mathrm{PA})}-[0,0160 \mathrm{Ca} \mathrm{(PA}]^{2}, \mathrm{R}^{2}=0,99 * * \\
\mathrm{MST}=-2,37+1,793 \mathrm{Ca}_{(\mathrm{R})}-\left[0,1605 \mathrm{Mg}_{(\mathrm{R})}\right]^{2}, \mathrm{R}^{2}=0,90 * *
\end{gathered}
$$

Assim, a máxima produção de matéria seca foi obtida quando os teores de Ca atingiram 12,0 $\mathrm{g} \mathrm{kg}^{-1}$. Na literatura é indicado, como adequado para o maracujazeiro, um teor foliar de $\mathrm{Ca}$ entre 12-16 $\mathrm{g} \mathrm{kg}^{-1}$ (Quaggio et al., 1996). Comparando-se esses teores com os do experimento, nota-se que o Ca está dentro do teor considerado adequado, porém se deve considerar as diferenças entre as partes de tecido amostrado, sendo que na planta adulta se coleta a folha (com botão floral na axila) e, nas mudas, a parte aérea total (caule + folhas).

Observou-se, ainda, relação positiva entre as concentrações de Ca do solo e a produção de matéria seca total $(\mathrm{MST}=-0,82$ $\left.+0,272 \mathrm{Ca}_{\text {(solo) }}-\left[0,0045 \mathrm{Ca}_{\text {(solo) }}\right]^{2}, \mathrm{R}^{2}=0,98 * *\right)$; desta forma, as concentrações de $\mathrm{Ca}$ do solo de $19 \mathrm{mmol}_{\mathrm{c}} \mathrm{dm}^{-3}$, estiveram associadas à máxima produção de matéria seca das mudas de maracujazeiro.

Ressalta-se que, com o uso deste resíduo como corretivo de acidez em solos com teor de Mg baixo, torna-se importante acrescentar uma fonte de $\mathrm{Mg}$, a exemplo do calcário (dolomítico), que apresenta custo unitário deste nutriente menor que as demais fontes comerciais.

\section{CONCLUSÃO}

O maior crescimento das mudas de maracujazeiro esteve associado à saturação por bases do solo de 58\%, à concentração de Ca do solo de $19 \mathrm{mmol}_{\mathrm{c}} \mathrm{dm}^{-3}$ e a teores de Ca na parte aérea de $12,0 \mathrm{~g} \mathrm{~kg}^{-1}$. 


\section{LITERATURA CITADA}

Alcarde, J.C. Corretivo de acidez dos solos: características e interpretações técnicas. São Paulo: Associação Nacional para Difusão de Adubos e Corretivos Agrícolas, 1992.26p. Boletim Técnico, 6

Almeida, J.R. de O problema da vinhaça em São Paulo. Piracicaba: ESALQ, Instituto Zimotécnico, 1952. 9p. Boletim, 3

Bataglia, O.C.; Furlani, A.M.C.; Teixeira, J.P.F.; Furlani, P.R.; Gallo, J.R. Métodos de análise química de plantas. Campinas: Instituto Agronômico, 1983.48p. (Boletim Técnico, 78

Berton, R.S. Potencial agrícola do composto de lixo urbano. In: Congresso Latino-Americano de Ciência do Solo, 13., Águas de Lindóia, 1996. Anais... Campinas, Sociedade Brasileira de Ciência do Solo, 1996. CD-Rom

Ferri, M.G. Fisiologia vegetal. São Paulo: EPU, 1985.362p.

Fonseca, E.B.A.; Carvalho, J.G.; Corrêa, J.B.D.; Pasqual, M. Crescimento do maracujazeiro doce em função da calagem. In: Congresso Brasileiro de Fruticultura, 17., Belém, 2002. Resumos... Belém: SBF, EMBRAPA Oriental, 2002. CD-Rom

Lima, A.A. A cultura do maracujá. Cruz das Almas: Embrapa Mandioca e Fruticultura, 1999.107p. Coleção plantar, 41

Machado, R.A.F. Fósforo e zinco na nutrição e crescimento de mudas de maracujazeiro amarelo (Passiflora edulis $f$. flavicarpa Deg.). Lavras: UFLA, 93p. 1998. Dissertação Mestrado

Malavolta, E. Manual de química agrícola: adubos e adubação. 3.ed. São Paulo, Agronômica Ceres, 1981. 594p.

Mendonça, R.M.N.; Coelho, A.F.S.; Martinez, H.E.P.; Fontes, P.C.R.; Pereira, P.R.G. Resposta de mudas de maracujáamarelo (Passiflora edulis Sims. F.flavicarpa Deg.) cultivadas em solução nutritiva, a diferentes níveis de alumínio. Ceres, Viçosa,v.46, n.266, p.357-370, 1999.
Oliveira, F.C.; Marques, M.O.; Bellingieri, P.A.; Perecin, D. Lodo de esgoto como fonte de macronutrientes para a cultura do sorgo granífero. Scientia Agricola, Piracicaba, v.52, p.360367, 1995.

Piza Júnior, C.T.; Quaggio, J.A.; Silva, J.R.; Kavati, R.; Meletti, L.M.M.; São José, A.R. Adubação do maracujá. In: Raij, B.Van.; Cantarella, H.; Quaggio, J.A.; Furlani, A.M.C. Recomendações de calagem e adubação para o Estado de São Paulo. Campinas: Instituto Agronômico, 1996. p.148149.

Prado, R.M.; Fernandes, F.M.; Natale, W. Uso agrícola da escória de siderurgia no Brasil: estudos na cultura da canade-açúcar. Jaboticabal: FUNEP, 67p. 2001.

Quaggio, J.A.; Raij, B. van.; Piza Júnior, C.T. Frutíferas. In: Raij, B. van.; Cantarella, H.; Quaggio, J.A.; Furlani, A.M.C. Recomendações de calagem e adubação para o Estado de São Paulo. Campinas: Instituto Agronômico, 1996. p.121127.

Raij, B.van. Fertilidade do solo e adubação. São Paulo: Ceres/ Potafós, 1991.343p.

Raij, B.van.; Andrade, J.C.; Cantarella, H.; Quaggio, J.A. (eds.) Análise química para avaliação da fertilidade do solo. Campinas: Instituto Agronômico, 2001. 285p.

Tescaro, M.D. Eficiência do método da saturação de bases para a correção da acidez de um solo Álico. In: Reunião Brasileira de Fertilidade do Solo e Nutrição de Plantas, 23.1998. Caxambu, Resumos... Lavras: Universidade Federal de Lavras, Sociedade Brasileira de Ciência do Solo, Sociedade Brasileira de Microbiologia, p.103, 1998.

Vale, F.R. do; Guilherme, L.R.; Guedes, G.A.; Furtini Neto, A.E. Fertilidade do solo: Dinâmica e disponibilidade dos nutrientes de plantas. Lavras: UFLA/FAEPE, 1997. 171p. 